\title{
Microstructure and mechanical properties of aluminum 5083 weldments by gas tungsten arc and gas metal arc welding
}

\author{
Yao Liu ${ }^{a}$, Wenjing Wang ${ }^{b}$, Jijia Xie ${ }^{a}$, Shouguang Sun ${ }^{b}$, Liang Wang c , Ye Qian ${ }^{a}$, Yuan Meng a , Yujie Wei ${ }^{a, *}$ \\ a State Key Laboratory of Nonlinear Mechanics, Institute of Mechanics, Chinese Academy of Sciences, Beijing 100190, PR China \\ ${ }^{\mathrm{b}}$ School of Mechanical, Electronic and Control Engineering, Beijing Jiaotong University, Beijing 100044, PR China \\ ${ }^{\mathrm{c}}$ College of Metallurgy and Material Engineering, Chongqing University of Science and Technology, Chongqing 401331, PR China
}

\section{A R T I C L E I N F O}

\section{Article history:}

Received 29 August 2011

Received in revised form 23 February 2012

Accepted 27 March 2012

Available online 11 April 2012

\section{Keywords:}

Gas tungsten arc welding

Gas metal arc welding

Aluminum 5083

Strength

Failure

\begin{abstract}
A B S T R A C T
The mechanical properties and microstructural features of aluminum 5083 (Al5083) weldments processed by gas tungsten arc welding (GTAW) and gas metal arc welding (GMAW) are investigated. Weldments processed by both methods are mechanically softer than the parent material Al5083, and could be potential sites for plastic localization. It is revealed that Al5083 weldments processed by GTAW are mechanical more reliable than those by GMAW. The former bears higher strength, more ductility, and no apparent microstructure defects. Perceivable porosity in weldments by GMAW is found, which could account for the distinct mechanical properties between weldments processed by GTAW and GMAW. It is suggested that caution should be exercised when using GMAW for Al5083 in the high-speed-train industry where such light weight metal is broadly used.
\end{abstract}

(c) 2012 Elsevier B.V. All rights reserved.

\section{Introduction}

Both Gas tungsten arc welding (GTAW) (also known as tungsten inert gas (TIG) welding) and Gas metal arc welding (GMAW) are broadly used industrial processes to weld aluminum [1-4], in particular for the aircraft industry where light weight metals like aluminum and magnesium alloys are commonly used. Meanwhile light weight alloys like Al5083 is also used to replace steels in modern high speed trains (HSTs), which can effectively reduce the energy consumption and consequentially lower carbon emission. In contrast to other types of high speed transport, HSTs owe their uniqueness in terms of mechanical environments they are embedded in. At an operation speed about $300 \mathrm{~km} / \mathrm{h}$, combination of the following effects such as ground aerodynamics (the interaction of moving trains with ground), interaction between trains passing each other, and tunnel effects (interaction between a train and tunnels) generates high stresses in those joints like weldments. A typical example of such is shown in Fig. 1. In Fig. 1a, we show the preparation of a strain gauge for in situ stress monitoring in a weldment connecting two Al5083 pieces. The dynamic stress in the weldment, as two trains pass by, is shown in Fig. 1b. The dynamic stress is found to be on the magnitude of tens of MPa, and is one to two orders of magnitude greater than the expected

\footnotetext{
* Corresponding author. Fax: +86 (10) 82543977.

E-mail address: yujie_wei@Inm.imech.ac.cn (Y. Wei).
}

number in static situation. Due to the presence of such high level dynamic stress, cracks commonly initiate from those weldments after a HST has been under service for a certain mileage, as seen in Fig. 1c.

With the rapid spreading of high speed railway grid in highly populated regions like Europe and Asia, it is of significance to enhance the structural reliability of HSTs and hence reduce their expenses for maintenance. Along this line, the broadly used weldments to join aluminum components is of technological significance. Specifically, it is desired to understand the mechanical properties of GTAW and GMAW welded weldments in many HSTs given the popularity of those two types of weldments used in HSTs. The type of weldments joining aluminum 5083 (Al5083) components are investigated here. They have the virtue of being broadly used in nowadays HSTs in China for their well balanced strength, weldability, and formability in contrast to weldments of other types. Some structural and mechanical properties [4-7] of Al5083 and their weldments have been investigated [8-13]. For example, mechanical properties of Al5083 using semi-automatic and automatic pulsed gas metal arc welding were investigated, and it was reported that both welding methods cause considerable softening in the weldments. In addition, automatic GMAW exhibits improved mechanical properties than semi-automatic GMAW [4]. Studies on the microstructure and mechanical property of friction stir welded Al5083 showed that the decrease in friction heat flow results in the refinement of grain size, higher ductility and better formability $[10,11]$. Microstructure of two different kinds of porosity 

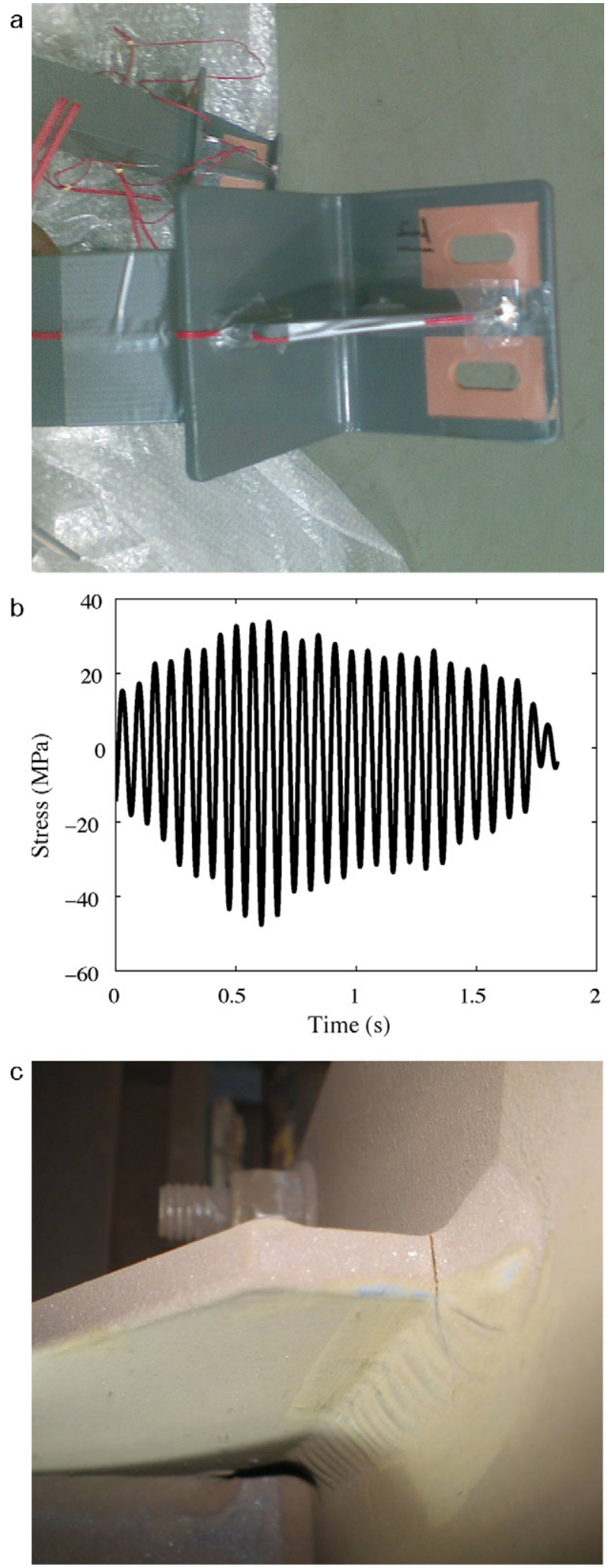

Fig. 1. Stress and deformation in a typical Al5083 weldment in HSTs. (a) Strain gauge setup for dynamic stress measurement in an Al5083 weldment. (b) Dynamic stresses in the welding zone as a function of time during two trains passing each other. (c) Formation of a crack in such welds after service for a period.
Table 1

Summary of welding conditions applied for both GMAW and GTAW. Note that the cooling rate is also temperature dependent. An average cooling rate is used here.

\begin{tabular}{lll}
\hline Specification & GMAW & GTAW \\
\hline Preheating & No & No \\
Welding current & $\begin{array}{l}\text { Direct current, } \\
\text { reverse polarity }\end{array}$ & $\begin{array}{l}\text { Alternating current } \\
\text { (AC) }\end{array}$ \\
& $($ DCRP) & \\
Welding voltage & $20-23$ & - \\
Shielding gases & $70 \% \mathrm{Ar}+30 \% \mathrm{He}$ & $100 \% \mathrm{Ar}$ \\
Shielding gases flow rate & $2.5-3 \times 10^{-4} \mathrm{~m}^{3} / \mathrm{s}$ & $1.8-2.2 \times 10^{-4} \mathrm{~m}^{3} / \mathrm{s}$ \\
Welding travel speed & $8.6-9 \times 10^{-3} \mathrm{~m} / \mathrm{s}$ & $1.5-1.8 \times 10^{-3} \mathrm{~m} / \mathrm{s}$ \\
Arc temperature & $\sim 5000 \mathrm{~K}$ & $\sim 6000 \mathrm{~K}$ \\
Cooling rate & $\sim 200 \mathrm{~K} / \mathrm{s}$ & $\sim 300 \mathrm{~K} / \mathrm{s}$ \\
Post-heating & No $/ 573 \mathrm{~K}$ & No \\
\hline
\end{tabular}

generated during laser welding of Al5083 aluminum alloys were also examined, and it was found that surface preparation and two dual beam welding should be applied to reduce the porosity formation tendency in laser assemblies [12].

The focus here is to understand the microstructures and mechanical properties of two types of welding methods applied to Al5083. We investigate the properties of Al5083 weldments processed by GTAW and GMAW techniques via a series of well controlled experiments. We show that weldments by GTAW bear higher strength, more ductility, and no apparent microstructure defects, while there is perceivable amount of porosity in weldments by GMAW method. It is suggested that caution should be exercised when using GMAW method for Al5083 in HSTs where such welding technique is adopted.

\section{Experimental procedures}

\subsection{Sample preparation and microstructure examination}

The samples were taken from butt welded pieces from the factory (China CNR Tangshan Railway Vehicle Co.) with Al5083 being the base metal. Pre-weld cleaning of weld joint surfaces was performed, in order to remove grease, rust, moisture in $20-30 \mathrm{~mm}$ distance of the groove on both sides. A summary of welding conditions applied for both GMAW and GTAW is listed in Table 1. For comparison, we also did post-heat to the GMAW weldments at $573 \mathrm{~K}$ for $30 \mathrm{~min}$, and then cool the samples to room temperature in $4 \mathrm{~h}$ in a heat chamber.

To examine the microstructures around the weldments, we prepared samples by cutting off a weldment in the transverse direction. Samples were first polished by using silicon carbide waterproof electro coated abrasive papers from CW400 to CW2000, and were then polished in 5\% perchloric acid and 95\% ethanol electrolyte for $1 \mathrm{~min}$ at $20 \mathrm{~V}$ and $1.5 \mathrm{amp}$, followed by etching in $12.5 \%$ nitric acid and $2.5 \%$ hydrofluoric acid aqueous solution for $1 \mathrm{~min}$. Grain structures were examined by using an optical microscopy POLYVAR MET in polished and etched samples (see Figs. 2 and 3). Scanning electron microscope (SEM) was also used to identify grain size and porosity in the weldments.

\subsection{Vickers micro-hardness tests}

The polished and etched samples were used for micro-hardness test. The Vicker micro-hardness in the middle of the weldments were measured by using micro-hardness tester MH-5L. For the parent material, we randomly choose the sites for hardness tests. For both the weldment and the parent material, we performed hardness tests in 25 sites. The typical distance between the two neighboring sites is above $500 \mu \mathrm{m}$ to avoid possible interference 

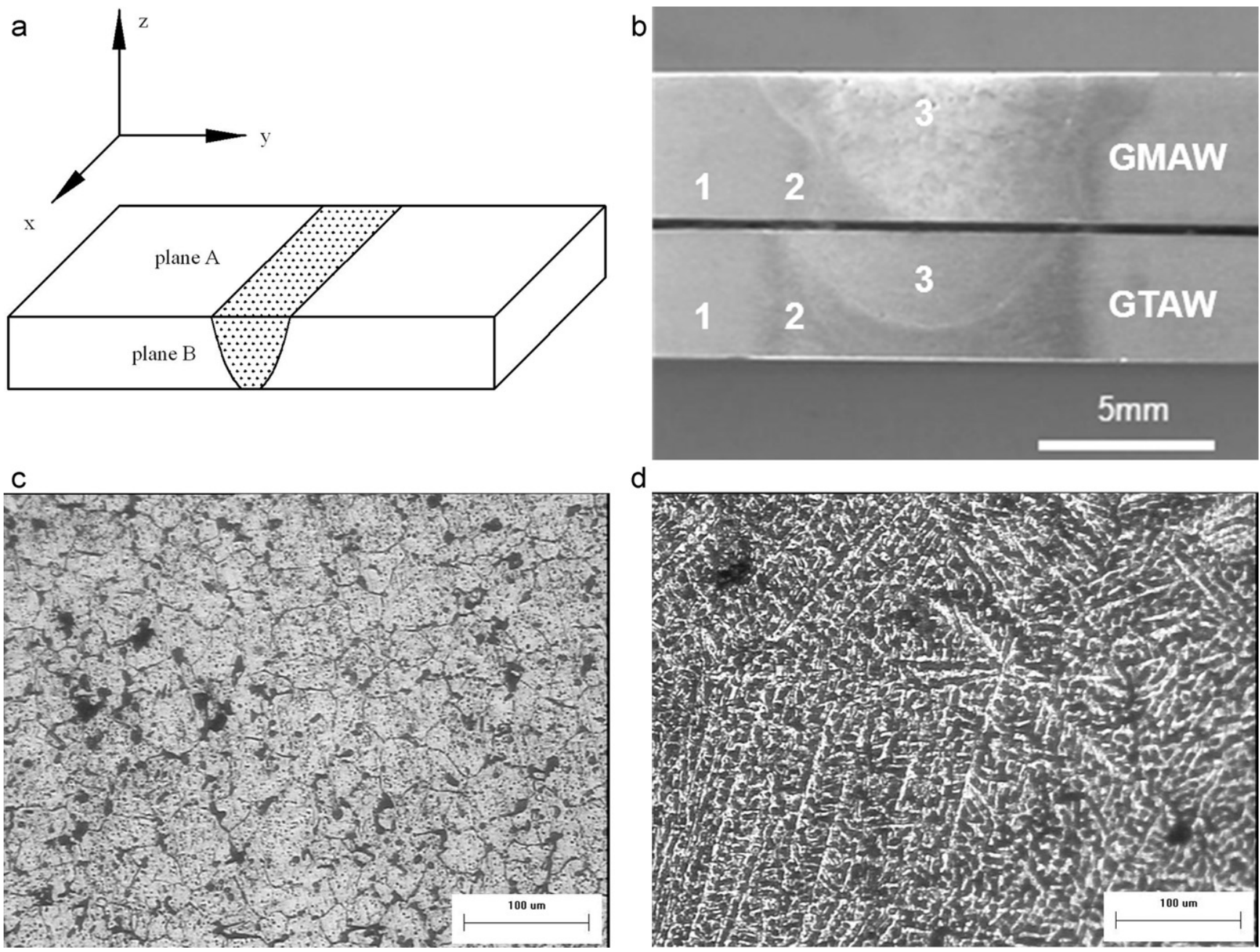

d

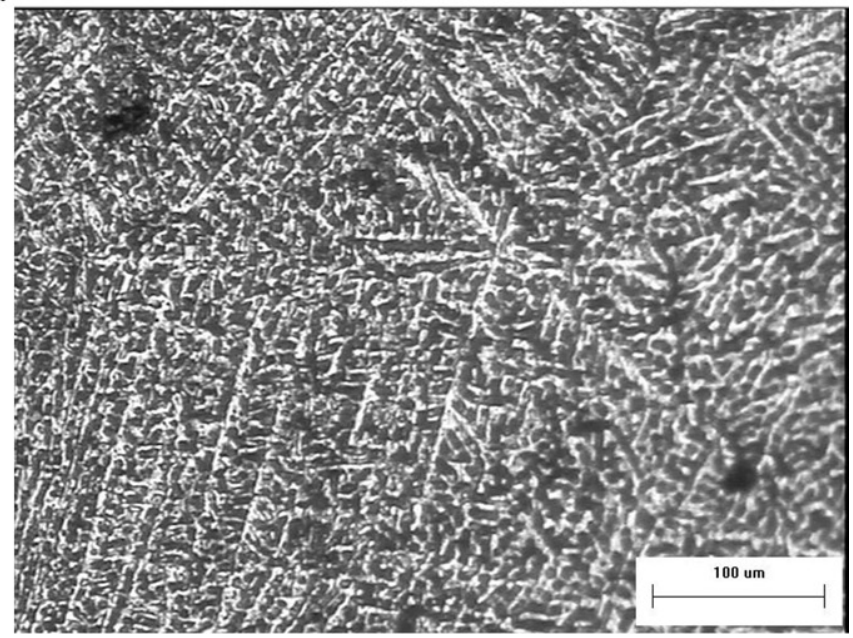

Fig. 2. Macroscopic and microscopic view of the welding zones. (a) The local coordinate. (b) Macroscopic images of welding zones viewed from the $x$-axis (top for GMAW and bottom for GTAW), regions marked by 1,2, and 3 refer to parent material, heat affected zone, and fusion zone, respectively. Amplifications to show microstructures for: (c) GTAW fusion zone, and (d) GMAW fusion zone.

of measurements. The software SVDM (Version 3.98) was used to measure the diagonal lengths of an indentation, and was then used to obtain the Vicker micro-hardness.

\subsection{Quasi-static uniaxial compression and tension}

Cylindrical rods of $7.5 \mathrm{~mm}$ in length and $3 \mathrm{~mm}$ in diameter were cut from the parent material and the weldments for quasistatic uniaxial compression. The experiment was carried out by using a material testing machine MTS810, with a strain rate about $4 \times 10^{-4} \mathrm{~s}^{-1}$.

For quasi-static uniaxial tensile experiments, we cut dog-bone specimens with a gauge length of $95 \mathrm{~mm}$, a gauge width of $20 \mathrm{~mm}$, and a sample thickness of $5 \mathrm{~mm}$. For the welded samples, the weldment locates in the middle of a sample, and is typically $10 \mathrm{~mm}$ wide. The samples were also strained at the rate of $4 \times 10^{-4} \mathrm{~s}^{-1}$. SEM S-507 was then used to examine the fractured surfaces.

In situ tensile experiments were also conducted to closely check the deformation process in the weldments. For this purpose, the used parts with weldments in a HST were cut into dog-bone specimens with a gauge length of $16 \mathrm{~mm}$, a gauge width of $4 \mathrm{~mm}$, and a sample thickness of $0.45 \mathrm{~mm}$. In the middle of the specimens are weldments with a typical width about $6 \mathrm{~mm}$. Sample
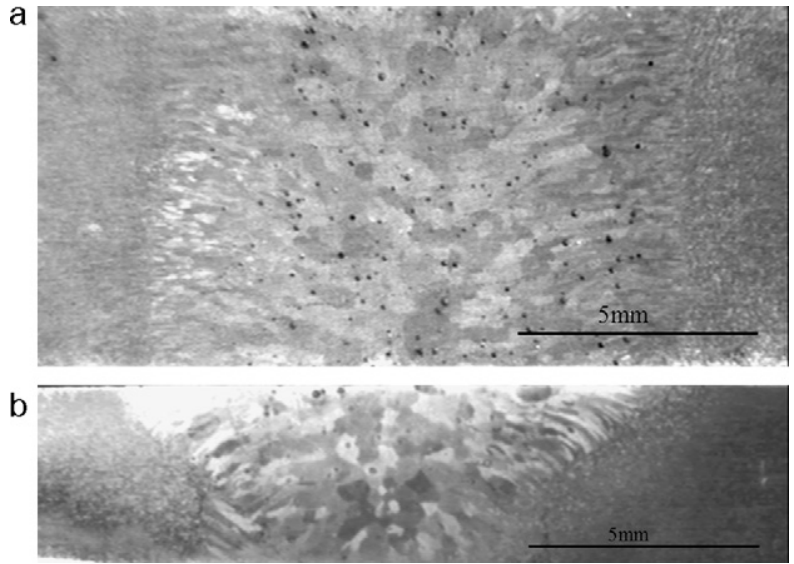

Fig. 3. Optical image of a GMAW welding zone, showing grain transition from columnar (neighbor to parent materials) to equiaxed (middle), and a large quantity of porosity can be observed in the welding zone (black spots). (a) Observed microstructures in plane A (viewed from $z$-axis in Fig. 2a), and (b) was observed from $x$-axis (plane B in Fig. 2a), where inclined columnar grains are clearly observed. 

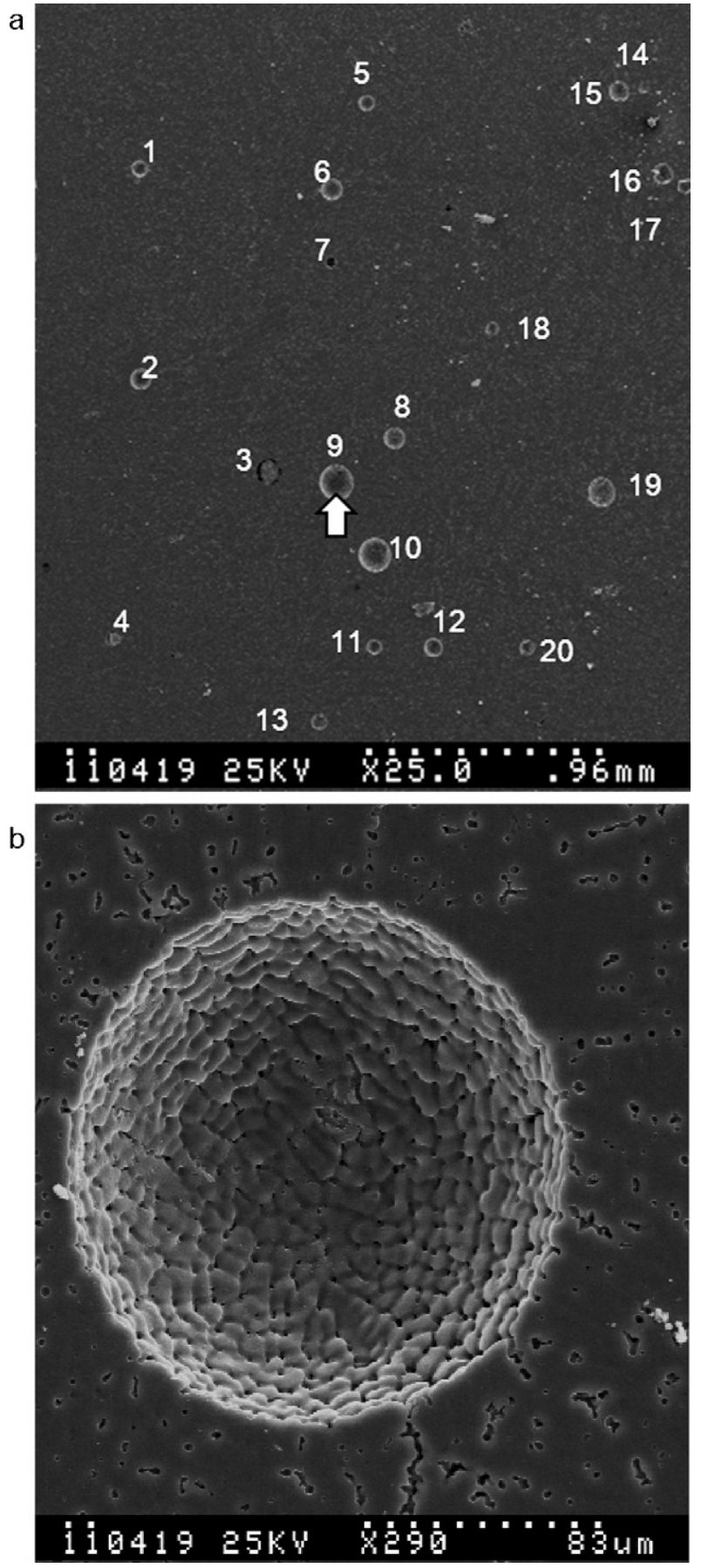

Fig. 4. Scanning electron microscopy of the microstructure of (a) GMAW weldments, and (b) close-ups of a typical spherical porosity in the region pointed by the white arrow in (a).

surfaces are prepared by the same procedures used for microstructure observation.

\section{Results}

The microstructures of the two types of weldments are given in Fig. 2. With the coordinate given in Fig. 2a, we see clearly the fusion zones, the heat affected zones, and the parent materials in Fig. 2b. Fig. 2c shows a homogeneous non-directional equiaxed grain structure in the middle of the GTAW weldment. The average grain size is around $38 \mu \mathrm{m}$. Fig. $2 \mathrm{~d}$ shows a typical directional solidified microstructure in the middle of the GMAW weldment. The

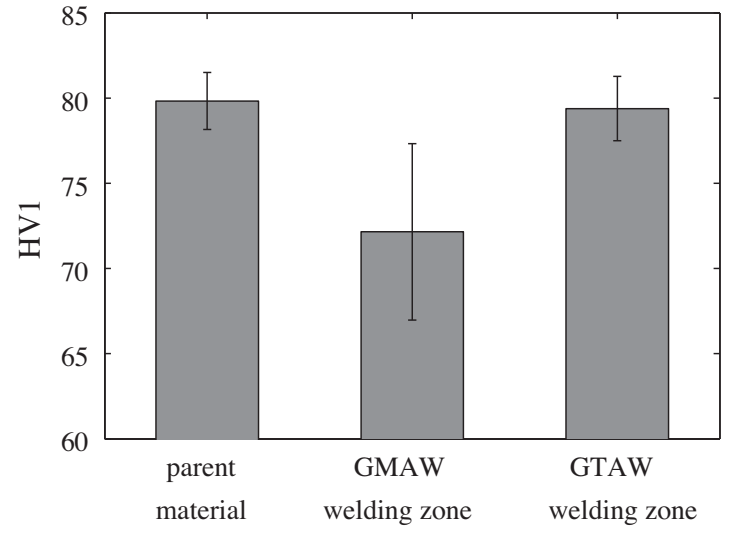

Fig. 5. Vickers micro-hardness of parent material, GMAW and GTAW weldments.

solidified grain structures varying from columnar to equiaxed could be resulted from the difference in solidification velocity [14]. In general, GTAW has slower melt convection than GMAW [15]. Therefore, solidification interfaces in GTAW welds develop slowly and result in steadily growing coarse crystals. On the contrary, GMAW welds solidify faster to form growing dendritic crystals and finer crystals. Compared with the two completely different solidified microstructures in the welding zones, it can be concluded that GTAW and GWAW welds have a significant difference in temperature gradient which could influence recrystallization.
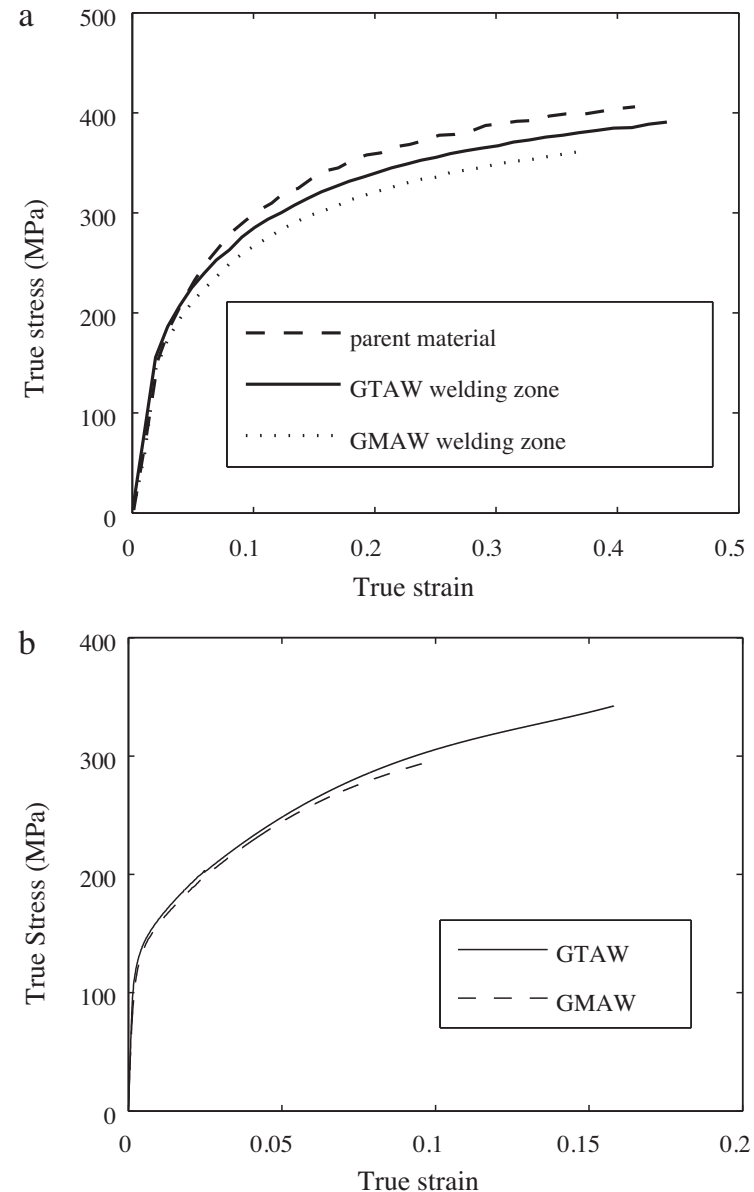

Fig. 6. Stress-strain curves for processed materials: (a) compressive stress-strain (true) curve of parent material Al5083, GTAW and GMAW weldments; (b) tensile stress-strain (true) curve of GTAW and GMAW weldments. 

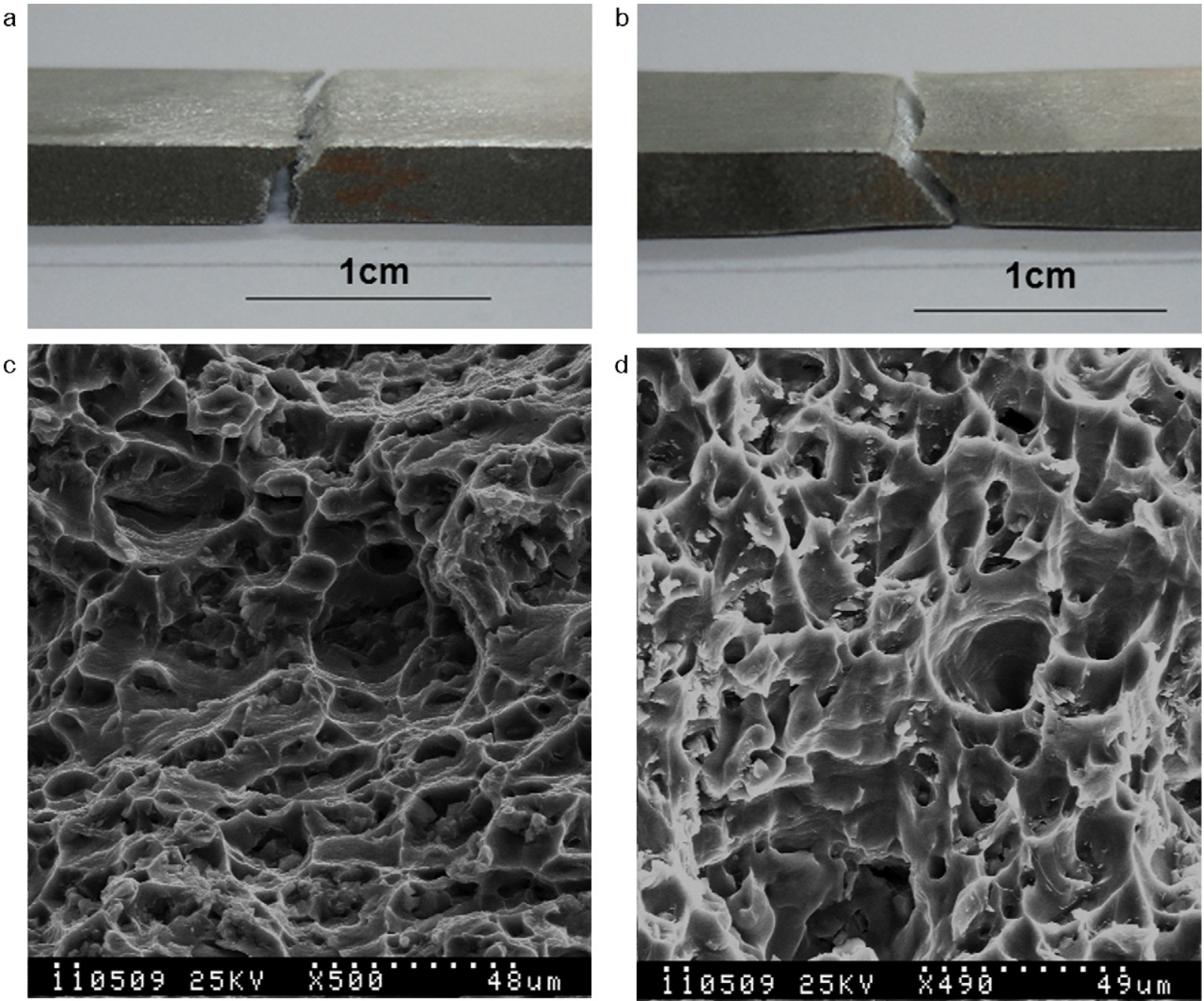

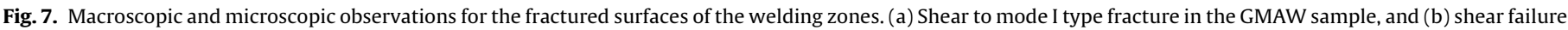
in the GTAW sample. SEM pictures to show dimples produced during the fracture of (c) the GMAW sample, and (d) the GTAW sample.

Electrolytic polished samples with GMAW weldments were used to show the microstructure of the weldments and the parent material in welding direction, see Fig. 3. Microstructures viewed from both the welding plane (Fig. 3a) and that along the welding path (Fig. 3b) are presented. In Fig. 3b, we see inclined columnar grains due to the inhomogeneous heat and cooling during welding. In addition, grains transform from columnar crystals to equiaxed crystals, and grain coarsening is observed from the parent material to the middle of the weldment. In addition, there is a large amount of porosities in the weldment, especially in equiaxed crystal zone. The average grain size in the GMAW fusion zone is about $11 \mu \mathrm{m}$ (see Fig. 4b).

We note the transition in grain shape from columnar to equiaxed is not observed in GTAW samples. From the parent material to the middle of the weldment, equiaxed grains distribute uniformly in GTAW samples, while grains in the heat affected zone are slightly larger than those in the fusion zone. The grain size in the fusion zone of the GTAW weldment is about $38 \mu \mathrm{m}$, as shown in Fig. 2b, which is apparent larger than that in the fusion zone of the GMAW weldment. It is further noted that in the GMAW weldment, our observation by using SEM shows the existence of porosity (Fig. 4a). It can be seen that spherical pores distribute randomly in the observation window. The averaged number density for pores is about $2.5 \mathrm{~mm}^{-2}$. Pores with typical diameters falling between $28.8 \mu \mathrm{m}$ and $148.8 \mu \mathrm{m}$, with an average diameter of $77.3 \mu \mathrm{m}$. Fig. $4 \mathrm{~b}$ shows the close-up of a typical spherical pore marked by the arrow in Fig. 4a. Grain boundaries are shown inside the spherical pore which indicates the grain size in GMAW weldments $(\sim 11 \mu \mathrm{m})$. To some extent, dissolved gases such as hydrogen, oxygen, and nitrogen, are always present in molten aluminum during welding. The porosity in GMAW weldments observed here is mostly attributed to hydrogen solubility in aluminum. As known, hydrogen has a high solubility in molten aluminum but a low solubility at the solid state, and such a discrepancy becomes even more significant in $\mathrm{Al}-\mathrm{Mg}$ alloys like Al5083 [4]. Supersaturation of hydrogen in the weld pool could be entrapped if solidification of the molten region is too fast to allow its complete volatilization. The relatively slower welding speed for GTAW compared to GMAW could be an effective way to reduce the probability of porosity formation. In addition, the sources of hydrogen in the two welding process could be another reason. For arc welding, possible hydrogen sources include the base metal, the filler metal, and the shielding gas [16]. Since we have adopted the same filler metal and the base metals, and shielding gases used for both cases are almost hydrogen free, we expect that the alternating current with electrode-positive polarity during GTAW serves as auxiliary cleaning process to remove possible surface oxides. During GMAW for Al5083, except the initial surface preparation, no additional action is taken to clean possible surface oxides. We also checked the GMAW weldments with post-heat to $573 \mathrm{~K}$ for $30 \mathrm{~min}$, and then cool the samples to room temperature in 
Table 2

Mechanical properties of the two types of welding zones from tensile tests.

\begin{tabular}{lcc}
\hline Properties & GMAW & GTAW \\
\hline Young's modulus (GPa) & 51.84 & 77.85 \\
0.2\% yield strength (MPa) & 132 & 133 \\
Ultimate tensile strength (MPa) & 269 & 296 \\
Percent elongation at fracture (\%) & 10.23 & 17.13 \\
Percent reduction in area at fracture (\%) & 12.45 & 25.85
\end{tabular}

$4 \mathrm{~h}$ in a heat chamber. No substantial difference in porosity is found between those post-heated GMAW weldments and those without heat treatment.

The Vicker micro-hardness of 5083 aluminum alloy is about $79.83 \pm 1.67 \mathrm{HV} 1$, and those in the GTAW and GMAW weldments are $79.38 \pm 1.89 \mathrm{HV} 1$ and $72.15 \pm 5.18 \mathrm{HV} 1$, respectively, as shown in Fig. 5. Vicker micro-hardness of the GTAW weldments is almost the same as that of the parent material, while that in the GMAW weldments is about $10 \%$ less than that of the parent material.

The mechanical responses of both the parent materials and the welding zones are shown in Fig. 6. Fig. 6a gives the quasi-static uniaxial compressive stress-strain curves for the parent material, GTAW and GMAW weldments. Here the ends represent the interruption of the tests at those point because there was no failure observed till the applied strain during compression. The quasistatic uniaxial tensile stress-strain behavior of GMAW and GTAW samples are shown in Fig. 6b. There is a striking difference in the ductility of the two types of weldments, by looking at the fracture points from the tensile stress-strain curves in Fig. 6b. The compressive strengths at 35\% strain are $396 \mathrm{MPa}$ for the parent material, $377 \mathrm{MPa}$ in the GTAW weldments, and $357 \mathrm{MPa}$ in the GMAW weldments. Typical mechanical properties of weldments processed by the two types of welding techniques are listed in Table 2. It is noted that we have tested at least two independent samples for each type of materials subjected to the same type of loading (either tension or compression). The obtained stress-strain curves for each type of test are highly repeatable.

Fractured surfaces of the GMAW and GTAW welded samples after tensile tests are shown in Fig. 7. Failure occurs in the weldments for both types of samples. From the macroscopic observations on the broken surfaces of the GMAW and GTAW welded samples, GTAW exhibits a ductile shear fracture in the whole fracture surface with a shear angle of $47^{\circ}$ (Fig. 7a), while the GMAW one exhibits a fibrous facture surface at one side and a shear fracture surface at another (Fig. 7b). Microstructure observations on the fractured surfaces for both GMAW and GTAW weldments are shown in Fig. 7c and d, respectively. They both have a gray, fibrous appearance. The dimples formed during the coalescence of microvoids suggest fracture in ductile manner. Fracture surfaces in GTAW welded samples have knife edged conical dimples, while dimple edges in the fracture surface of GMAW samples are smooth ellipses. These differences indicate more plastic deformation in GTAW samples than that in GMAW samples. Fig. 8 gives the optical images of a GTAW welded sample under in situ tension (see Fig. 8a for the initial sample). Large plastic deformation was observed in the weldment. Corresponding microstructures of the weldment before tension and that at about 7\% macroscopic tensile strain are shown in Fig. 8b and c, from which we can see equiaxed grains in as received samples changed into directionally extended grains along the shear band direction after tension. It suggests that a significant amount of localized plasticity could be achieved in GTAW weldments.

From microstructural observations, we see that grains in GMAW weldments are finer compared to GTAW weldments, which could give rise to high strength instead. In addition, the presence of
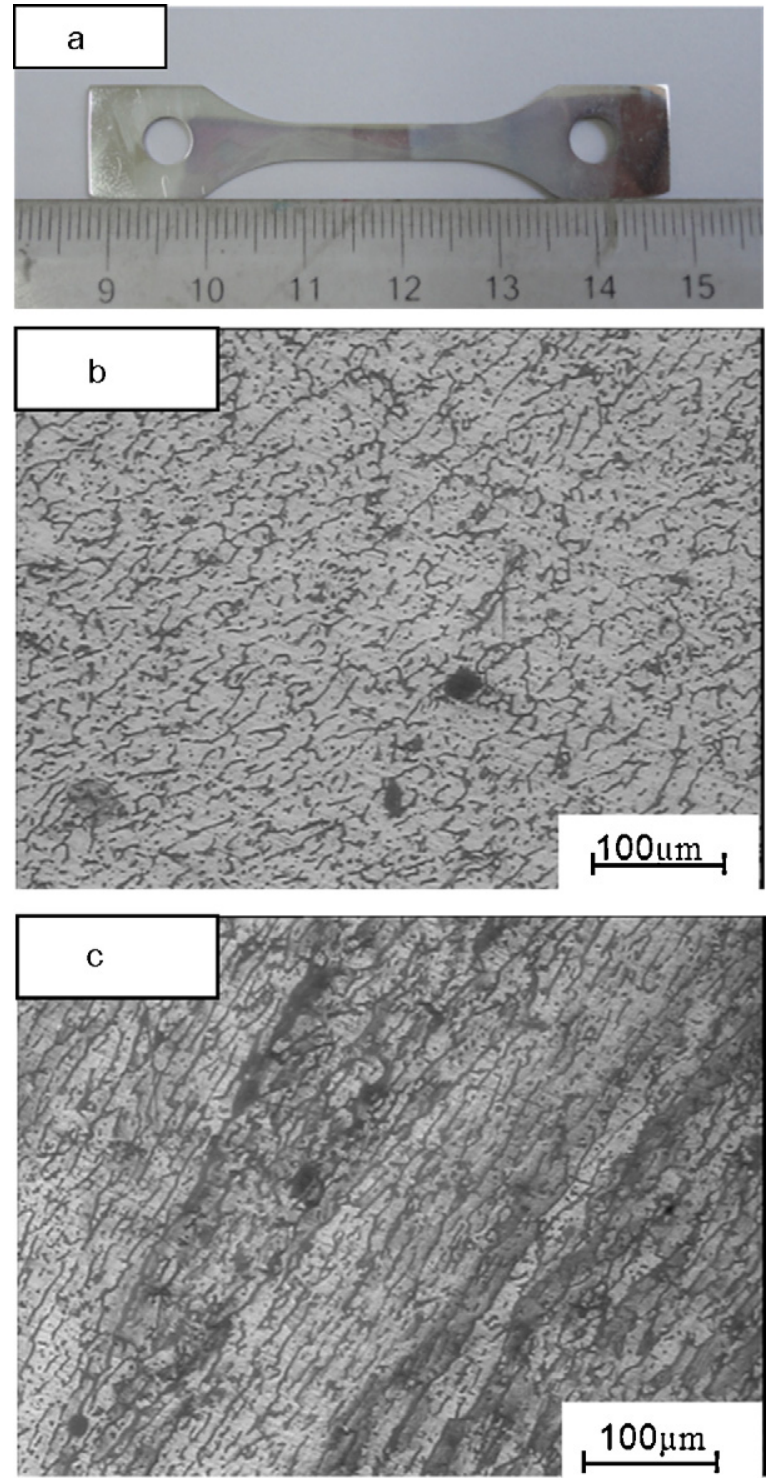

Fig. 8. In situ small-scale tensile test for a GTAW weldment. (a) The sample for the in situ test shows clearly the welding zone in the middle, which is about $5 \mathrm{~mm}$ in width. (b) Initial microstructures in the welding zone; (c) localized shear bands and large plastic deformation in welding zone after tensile test.

second phase particles may also influence the strength and ductility in those two types of weldments. Typically, chemical composition in $\mathrm{Al} 5083$ includes $\mathrm{Si}(0.4), \mathrm{Fe}(0.4), \mathrm{Cu}(<0.1), \mathrm{Mn}(0.4-1.0), \mathrm{Mg}$ (4.0-4.9), $\mathrm{Zn}(0.25), \mathrm{Ti}$ (0.15), $\mathrm{Cr}(0.05-0.25)$, and balanced $\mathrm{Al}$ at \%weight. The presence of those elements will form various kinds of intermetallics such as $(\mathrm{Mn}, \mathrm{Fe}) \mathrm{Al}_{6},(\mathrm{Cr}, \mathrm{Fe}) \mathrm{Al}_{7}$ or $\mathrm{Mg}_{3} \mathrm{Mn}_{2} \mathrm{Al}_{12}$ [17-19]. Further, in $\mathrm{Al}-\mathrm{Mg}$ alloys with high $\mathrm{Mg}$ content $(\sim 5 \% \mathrm{Mg})$, which is higher than the $1.9 \%$ equilibrium solubility of $\mathrm{Mg}$ in $\mathrm{Al}-$ matrix at room temperature, $\mathrm{Mg}$ solute atoms tend to precipitate out as an equilibrium $\beta$-phase $\left(\mathrm{Mg}_{5} \mathrm{Al}_{18}\right)$ along the grain boundaries or distributed in the structure. The presence of all those second phase particles serves as effective strengthening mechanisms. SEM pictures in Fig. 9a and b show respectively the presence of second phase particles in GMAW and GTAW weldments. Energy dispersive X-ray spectra (EDS) from the whole windows in Fig. 9a and $\mathrm{b}$ are collected respectively and processed by using the integrated Oxford INCA software. The collected elemental composition in GMAW weldments includes $\mathrm{Mg}$ (4.60), $\mathrm{Mn}$ (0.95), $\mathrm{Al}$ (94.45) at \%weight, while $\mathrm{Mg}$ (5.07), $\mathrm{Mn}$ (0.48), $\mathrm{Al}$ (94.45) at \%weight in GTAW 
Table 3

Statistics on second particle phases in GMAW and GTAW weldments based on Fig. 9a and b.

\begin{tabular}{|c|c|c|c|c|c|c|}
\hline & Total area $\left(\mu \mathrm{m}^{2}\right)$ & $\begin{array}{l}\text { Second phase } \\
\text { area }\left(\mu \mathrm{m}^{2}\right)\end{array}$ & $\begin{array}{l}\text { Average } \\
\text { particle size } \\
\left(\mu \mathrm{m}^{2}\right)\end{array}$ & $\begin{array}{l}\text { Second phase area } \\
\text { fraction }(\%)\end{array}$ & $\begin{array}{l}\text { Porosity area } \\
\left(\mu \mathrm{m}^{2}\right)\end{array}$ & $\begin{array}{l}\text { Porosity area } \\
\text { fraction (\%) }\end{array}$ \\
\hline GMAW & 98,576 & 8007 & 8.7 & 8.1 & 1918 & 1.9 \\
\hline GTAW & 97,415 & 2140 & 1.5 & 2.2 & 0 & 0 \\
\hline
\end{tabular}
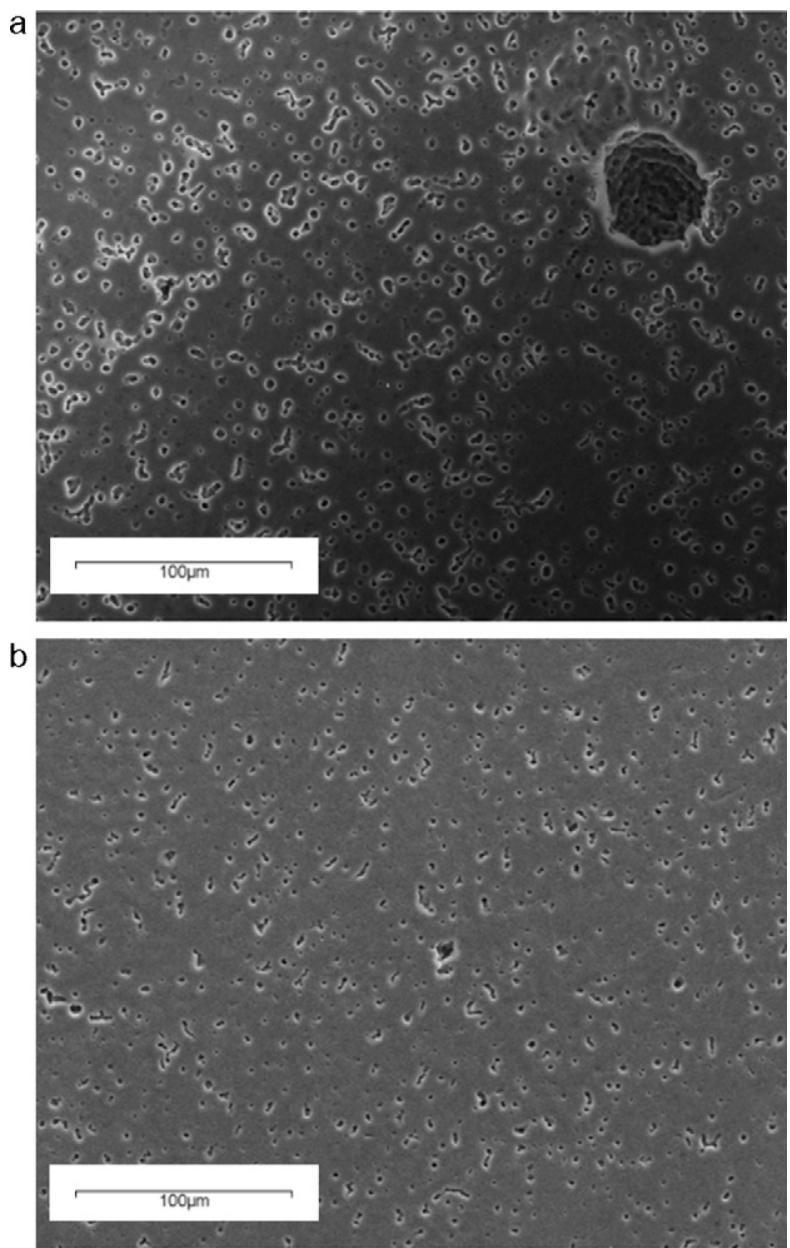

Fig. 9. SEM microstructure observations to show second phase particles in Al5083 weldments. (a) Microstructures for GMAW weldment; and (b) microstructures for GTAW weldment.

weldments. Due to resolution limitation, we are not able to determine other elements which may exist in the alloy. The \%weight for Mg in GMAW weldments is relatively less than that in GTAW weldments. We further show statistics in Table 3 on second particle phases in GMAW and GTAW weldments based on Fig. 9a and b. The fraction area of second phase particles in GMAW, as well as their average size, is much larger than those in GTAW weldments. Given that the second phase particles are much harder than their matrix and second phase area fraction in GMAW weldments is much higher than that in GTAW weldments, we could conclude that the strengthening factors of finer grain size and more second phase particles in GMAW weldments are cancelled out by the presence of significant amount of porosity. Porosity in Al5083 weldments by GMAW deteriorates its mechanical performance, which render them less reliable than Al5083 weldments by GTAW.

\section{Concluding remarks}

We investigated carefully two types of broadly used welding techniques for Al5083 structures, and revealed that: (a) GTAW and GMAW welding methods exhibit significantly different mechanical properties in Al5083 weldments. The former bears higher strength, more ductility, and without apparent microstructure defects, while there is perceivable number of porosity in GMAW weldments, which could account for the distinct mechanical properties between GTAW and GMAW weldments; (b) Al5083 structures bonded by GTAW are mechanical more reliable than those welded by GMAW. The slower welding speed and additional arc cleaning during GTAW in contrast to GMAW are regarded as the courses for no porosity in GTAW weldments but perceivable amount of porosity in GMAW. Porosity is indentified as the primary factor to deteriorate the mechanical properties of Al5083 weldments by GMAW. It is suggested that caution should be exercised to use GTAW for high speed trains or other industries (see. e.g. Ref. [20]) where light weight metals like Al5083 are broadly used. Further research on the fatigue properties of those weldments is desired, which could help us to assess the life time of structures made of Al5083 and connected by such weldments.

\section{Acknowledgements}

Y.W. thanks support from CAS (KJCX2-EW-L03) and 973 Project (2011CB711103). W.W. and S.S. gratefully acknowledge the financial support from Beijing Nova Program (2009B15) and the fundamental research funds for the central universities. Materials are supplied by China CNR Tangshan Railway Vehicle Co. LTD and Victall Railway Group.

\section{References}

[1] H.B. Cary, S.C. Helzer, Modern Welding Technology, Pearson Education, New Jersey, 2005.

[2] Lincoln Electric, The Procedure Handbook of Arc Welding, Lincoln Electric, Cleveland, 1994.

[3] J. Haidar, J. Appl. Phys. 84 (1998) 3518-3529.

[4] K. Mutombo, M.D. Toit, Mater. Sci. Forum. 654-656 (2010) 2560-2563.

[5] V.L. Tellkamp, E.J. Lavernia, Mater. Res. Soc. Symp. Proc. 12 (1999) 249-252.

[6] R.M. Cleveland, A.K. Ghosh, J.R. Bradley, Mater. Sci. Eng. A 351 (2003) 228-236.

[7] F. Tang, M. Hagiwara, J.M. Schoenung, Mater. Sci. Eng. A 407 (2005) 306-314.

[8] R. Goswami, G. Spanos, P.S. Pao, R.L. Holtz, Mater. Sci. Eng. A 527 (2010) 1089-1095.

[9] R.W. Davies, J.S. Vetrano, M.T. Smith, S.G. Pitman, J. Mater. Process. Technol. 128 (2002) 38-47.

[10] T. Hirata, T. Oguri, H. Hagino, T. Tanaka, S.W. Chung, Y. Takigawa, K. Higashi, Mater. Sci. Eng. A 456 (2007) 344-349.

[11] M. Peel, A. Steuwer, M. Preuss, P.J. Withers, Acta Mater. 51 (2003) 4791-4801.

[12] A. Haboudou, P. Peyre, A.B. Vannes, G. Peix, Mater. Sci. Eng. A 363 (2003) 40-52

[13] A. Anconaa, P.M. Lugara, D. Sorgente, L. Tricaric, J. Mater. Process. Technol. 191 (2007) 381-384.

[14] J.E. Spinelli, I.L. Ferreira, A. Garcia, J. Alloy. Compd. 384 (2004) 217-226.

[15] C.S. Wu, Eng. Computation 9 (1992) 529-537.

[16] R.P. Martukanitz, P.R. Michnuk, Aluminium 58 (1982) 276

[17] L. Dupuy, J.J. Brandin, Acta Mater. 50 (2002) 1251.

[18] R. Verma, A.K. Gosh, S. Kim, C. Kim, Mater. Sci. Eng. A 191 (1995) 143.

[19] K.T. Park, D.Y. Hwang, Y.K. Lee, Y.K. Kim, D.H. Shin, Mater. Sci. Eng. A 341 (2003) 273-281.

[20] A.P. Newbery, S.R. Nutt, E.J. Lavernia, JOM 58 (April) (2006) 56-61. 